\title{
Revisiting synchronous gamete release by fucoid algae in the intertidal zone: fertilization success and beyond?
}

\author{
Gareth A. Pearson ${ }^{1}$ and Ester A. Serrão \\ CCMAR, CIMAR-Laboratório Associado, FCMA, Universidade do Algarve, Gambelas, Faro 8005-139, Portugal
}

\begin{abstract}
Synopsis In the marine environment, both external fertilization and settlement are critical processes linking adult and early juvenile life-history phases. The success of both processes can be tightly linked in organisms lacking a larval dispersive phase. This review focuses on synchronous gamete release (= spawning) in fucoid algae. These brown macroalgae are important components of temperate intertidal ecosystems in many parts of the world, and achieve synchronous gamete release by integrating various environmental signals. Photosynthesis-dependent sensing of boundary-layer inorganic carbon fluxes, as well as blue light and green light signals, possibly perceived via a chloroplast-located photoreceptor(s), are integrated into pathways that restrict gamete release to periods of low water motion. Avoidance of turbulent and/or high flow conditions in the intertidal zone allows high levels of fertilization success in this group. Temporal patterns and synchrony of spawning in natural populations are reviewed. Most species/populations have a more or less semilunar periodicity, although phase differences occur both between and within species at different geographical locations, raising the possibility that tidal and diurnal cues are more important than semilunar cues in entraining the response. The ecological and evolutionary role(s) of synchronous spawning in the intertidal zone are considered, particularly with regard to hybridization/reproductive isolation in species complexes, and reproductive versus recruitment assurance in the intertidal zone, where synchronous spawning during calm periods may be important for recruitment assurance in addition to fertilization success. Ways in which the roles of spawning synchrony could be tested in closely related species with contrasting mating systems (outcrossing versus selfing) are discussed.
\end{abstract}

\section{Introduction}

Broadcast spawning and external fertilization are common in many groups of marine organisms, despite the pitfalls of ensuring reproductive success in the sea. Perhaps the single most important factor favoring successful syngamy is the synchronous release of gametes from reproductive individuals. Indeed, the literature contains many striking examples of spawning synchrony, from the Palolo worm in the south Pacific (see Caspers 1984) to the mass spawning of many species of corals (Harrison and others 1984; Babcock and others 1986). In these and other examples, organisms respond to 1 or more cues from multiple environmental cycles, including daily (light-dark), tidal, semilunar, lunar, and seasonal, to synchronize gamete release (Morgan and Christy 1994; Yamahira 2004; Skov and others 2005). Tight control over the timing of gamete release, and therefore sensitivity to environmental cues, is very important for reproductive assurance in externally fertilizing species. Until recently, the prevailing paradigm has been that sperm limitation is widespread in the sea (reviewed by Levitan and Petersen 1995; but also see Yund 2000). This conclusion is mainly based on experimental studies of induced spawning (for example, Pennington 1985; Levitan and others 1992) and theoretical considerations of the effects of turbulent flow regimes on gamete dilution rates in the water column (Denny and Shibata 1989). However, this view has increasingly come under scrutiny because of studies of natural spawning events, primarily in fucoid algae, in which fertilization rates close to $100 \%$ are typical for several species (Brawley 1992; Pearson and Brawley 1996; Serrão and others 1996; Berndt and others 2002; Ladah and others 2003). Similarly, realistic timeintegrated spawning patterns, using non-manipulated gametes and ecologically relevant flow rates, may modify the current view of broadcast spawning as a purely water column process (Yund and Meidel 2003).

Following syngamy, many of the most-studied broadcast-spawning invertebrates undergo a larval dispersal phase. In contrast, for fucoids and other species with direct development, spawning/fertilization and

\footnotetext{
From the symposium "Integrating Function over Marine Lifecycles" presented at the annual meeting of the Society for Integrative and Comparative Biology, January 4-8, 2006, at Orlando, Florida.

1 E-mail: gpearson@ualg.pt

Integrative and Comparative Biology, pp. 1-11

doi:10.1093/icb/icl030
}

(C) The Author 2006. Published by Oxford University Press on behalf of the Society for Integrative and Comparative Biology. All rights reserved. For permissions please email: journals.permissions@oxfordjournals.org. 
settlement/recruitment processes are tightly coupled. Variation in dispersal scales in the marine environment (Kinlan and Gaines 2003; Palumbi 2004) may thus be partially linked to life-history processes and constraints. Furthermore, the steep environmental gradients within the intertidal zone, and the narrow vertical ranges of many species, may confer fitness benefits on individuals that restrict dispersal. Long-distance dispersal of gametes or zygotes may result more in wastage of zygotes than in effective gene flow for species with fringe-like intertidal distributions and direct development, and for which long-distance dispersal may be mediated by other means (for example, via the transport of dislodged reproductive adult individuals in drift material). Thus, synchronous release of gametes can be critical for recruitment assurance in addition to reproductive assurance. Although tightly linked processes, we will argue that the relative importance of spawning synchrony for reproduction and recruitment might be dissected using fucoid models in which sympatric species have different reproductive modes, as well as different mating systems (hermaphroditic and selfing versus dioecious and outcrossing) (Engel and others 2005). This is possible because the predicted importance of synchrony for reproductive assurance, but not recruitment assurance, varies with mating system. The genus Fucus contains sibling species that occur in sympatry throughout much of their respective ranges. Asynchrony between species and synchrony within species may be under strong selection to reinforce prezygotic reproductive isolation and reduce the likelihood of hybridization (Gardner 1997; Fukami and others 2003; Levitan and others 2004).

The present review assesses our current understanding of synchronous spawning in fucoid algae (sensu Fucaceae), based on investigation of the proximal environmental cues to which fucoids respond, the signaling pathways and mechanisms by which gamete release is controlled, and the patterns of gamete release in natural populations. Ways in which this knowledge can be applied, or extended, is addressed as a means of resolving questions such as: To which environmental cycles are rhythmic spawning patterns entrained across species ranges? What is the degree of intraspecific synchrony and interspecific asynchrony in sympatric assemblages of sibling species? What is the relative importance of spawning synchrony for reproductive assurance versus recruitment assurance in the intertidal zone?

\section{Proximal environmental cues and signaling mechanisms for gamete release by fucoid algae: water motion and light sensitivity}

The reproductive tissue of most fucoids (sensu Fucaceae) develops as apical swellings termed receptacles (Fig. 1A), within which form many spherical or flask-shaped conceptacles containing the gametangia (both antheridia and oogonia in hermaphroditic species). Each conceptacle has an ostiole opening to the surface through which the gametangia are released during spawning (Fig. 1B). The gametangia then sink to the bottom. The gametangial membranes loosen and break down rapidly in contact with seawater to release eggs and sperm.

Observations linking gamete release and water motion in natural populations of fucoid algae were first made not in the intertidal zone, but in the nontidal Baltic Sea. Regular gamete release from the dioecious species Fucus vesiculosus (L.) in the Baltic occurred late in the afternoon, but appeared to be inhibited on days with higher than average wind-induced environmental water
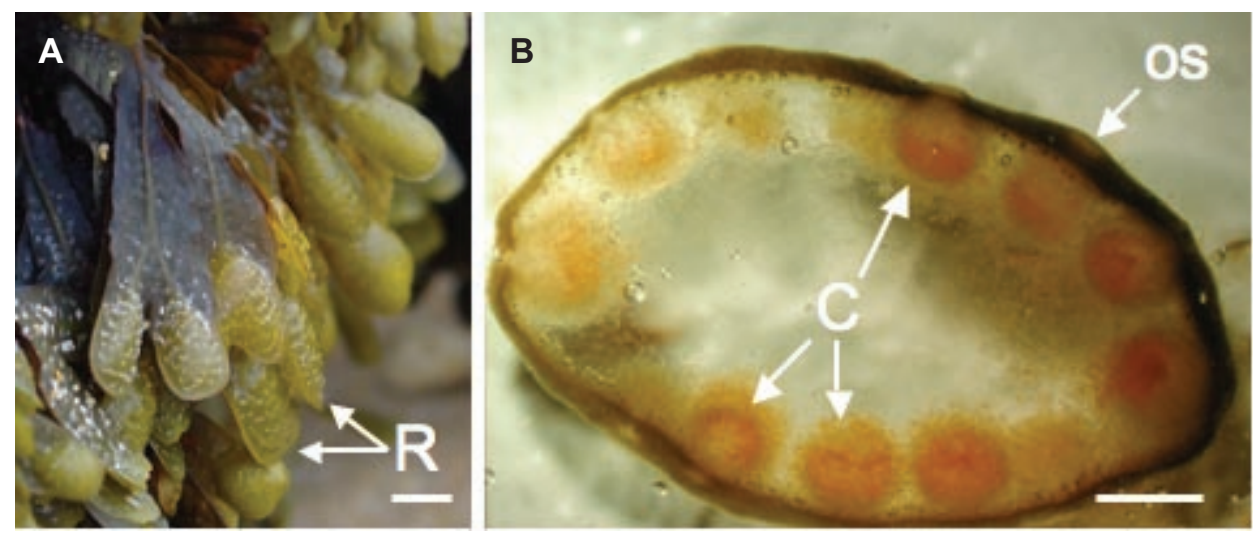

Fig. 1 Organization of reproductive tissue in fucoid algae. (A) Typical appearance of receptacles (R) forming at the branch tips of $F$. spiralis thalli. Scale bar $=1 \mathrm{~cm}$. (B) Lateral section through a receptacle ( $F$. vesiculosus, male individual) showing the conceptacles $(\mathrm{C})$, in which the gametangia are contained. During spawning, gametangia are released through the ostiole (os) to the receptacle surface. Scale bar $=1 \mathrm{~mm}$. 
motion (Serrão and others 1996). Experimental studies established that calm conditions were required for gamete release from both male and female algae; even short periods of agitation of cultured receptacles for $2 \mathrm{~h}$ prior to the natural release period inhibited gamete release, whereas extended periods of agitation were ineffective providing there was a $2 \mathrm{~h}$ period of calm prior to the optimal release period (Serrão and others 1996; Fig. 2). Thus, hydrodynamic conditions provide a powerful proximal signal controlling gamete release in F. vesiculosus.

Gamete release in natural populations of Fucus spp. occurs exclusively in the light (Pearson and Brawley 1996) and, as shown by Serrão and colleagues (1996) using an inhibitor of photosystem II electron transport, DCMU [3-(3,4-dichlorophenyl)-1,1-dimethylurea], requires active photosynthesis. A mechanism by which photosynthesis and hydrodynamic conditions could be directly linked was suggested by analogy with the guard cells of higher plants, in which photosynthetic $\mathrm{CO}_{2}$ supply is a signal controlling guard cell volume and stomatal opening (Assmann 1993). The hermaphroditic species Fucus distichus, which occurs

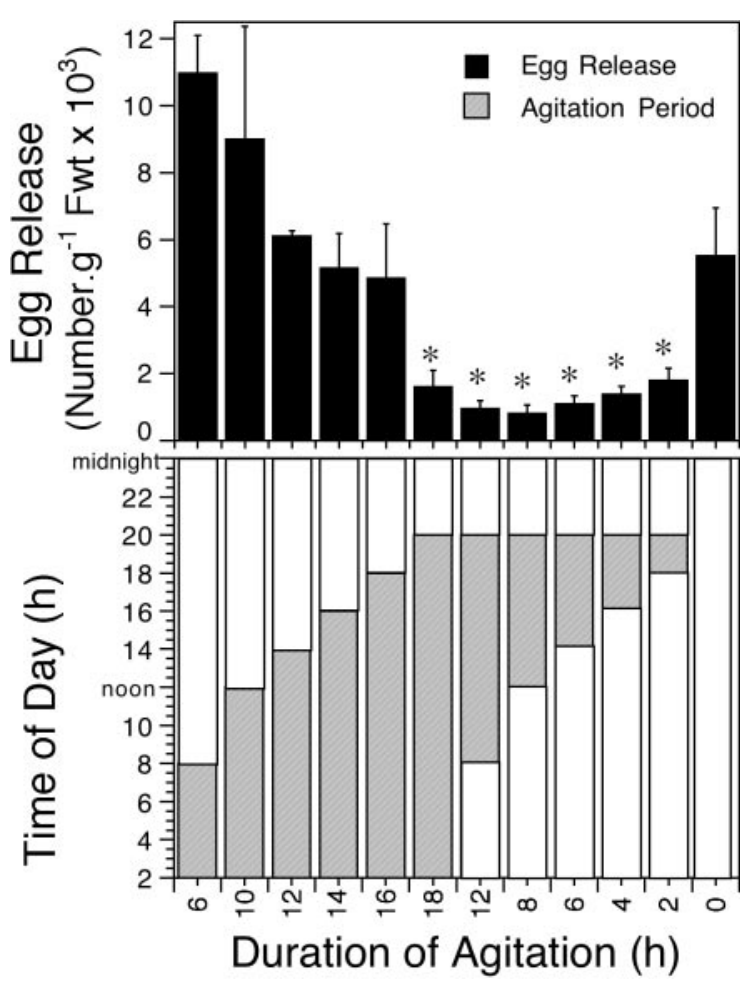

Fig. 2 Effect of time and duration of the period of agitation (provided by an orbital shaker, 150 r.p.m.) on the release of eggs (mean $\pm \mathrm{SE}$ ) from Baltic F. vesiculosus. Asterisks indicate results that differ significantly from the controls (no agitation) under calm conditions (from EA Serrão, G Pearson, L Kautsky, and SH Brawley, 1996, Successful external fertilization in turbulent environments, Proc Natl Acad Sci USA 93:5286-90). exclusively in high intertidal tidepools on the coast of Maine, USA, releases gametes during diurnal low tides for 1 or 2 concurrent days around the neap tide cycle (Pearson and Brawley 1996). At the scale of the semilunar cycle gamete release is synchronous between pools, and was found to correlate well with days on which dissolved inorganic carbon (DIC) became depleted by photosynthetic activity during the daytime low tide period (Pearson and others 1998; Fig. 3). Further experiments established that the "water motion sensor" does indeed act by detecting levels of DIC, which are depleted in the boundary layer around tissues under calm or low-flow conditions. Experiments in which the seawater $\mathrm{pH}$ was shifted to manipulate the $\mathrm{CO}_{2}-\mathrm{HCO}_{3}{ }^{-}-$ $\mathrm{CO}_{3}^{2-}$ equilibrium concentrations indicated that the effect could best be explained by $\left[\mathrm{HCO}_{3}{ }^{-}\right]$, the most abundant source of inorganic carbon in seawater (Pearson and others 1998). There was no evidence for a role for mechanosensing in controlling gamete release, which was found to be independent of water motion in DIC-free seawater.

While the environmental role of water motion/DIC sensing is well established, the cellular mechanisms and signaling pathways underlying gamete release are less completely understood. The model system used for these studies to date has been Silvetia compressa (Serrão and others 1999). Although in common with other fucoids $S$. compressa requires a period of carbonlimited photosynthesis (provided by calm conditions in the light) prior to gamete release, in laboratory cultures gametes are retained by receptacles in the light and are not released. Instead, gamete release is rapidly triggered by a transfer from light to darkness (Jaffe 1954). Two distinct phases of gamete release can therefore be identified, a potentiation phase dependent on light and photosynthesis, followed by a rapid gamete expulsion phase (see Pearson and Brawley 1998). The potentiation status of receptacles can be reversibly controlled in culture simply by changing the conditions of water motion (Fig. 4A and B), whereupon gamete expulsion in the dark can be rapidly assayed $(<5 \mathrm{~min}$ for completion) (Fig. 4C). This provided a convenient experimental system for assessing the effects of various inhibitors on hypothesized components of the potentiation process. Perhaps unsurprisingly, important roles for the activities of various ion channels were implicated; blocking S-type (slow) anion channels during potentiation caused premature release of gametes in the light, whereas blocking $\mathrm{K}^{+}$-channels with the tetraethylammonium ion $\left(\mathrm{TEA}^{+}\right)$during potentiation decreased subsequent release of gametes in the dark (Pearson and Brawley 1998). In the same study, potentiation was similarly inhibited by the biologically active sterioisomer of malate, which is known to activate 

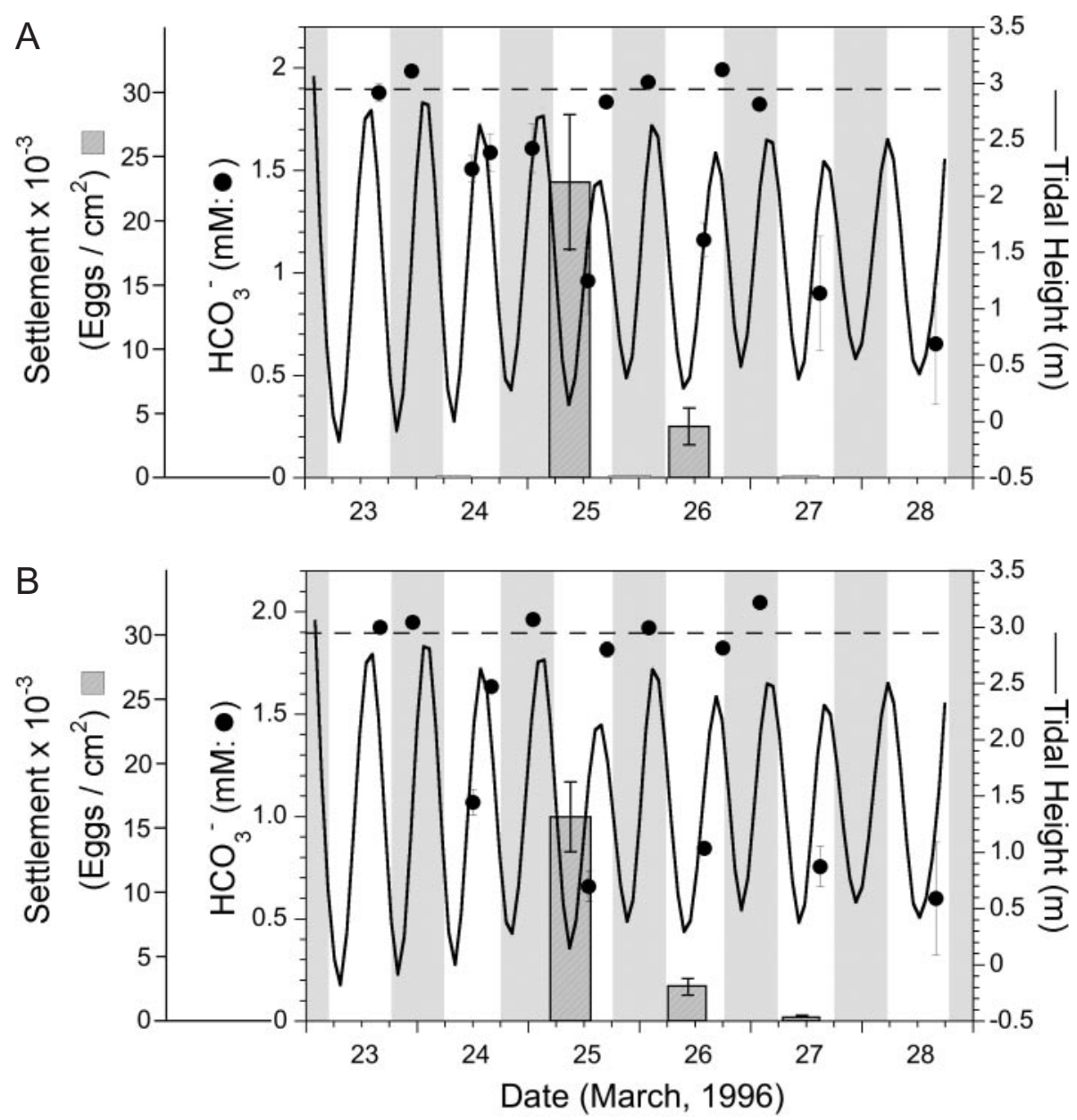

Fig. 3 Gamete release from F. distichus (determined from egg settlement on artificial substrates; $n=6 \pm$ SE) from tidepools A2 (A) and B4 (B) at Chamberlain, Maine, between March 23 and 28, 1996 (far left axis; the width of the bars illustrates the sampling intervals, separated by high-tide periods when the pools were being washed by waves). The bicarbonate concentration in the pools prior to, or just following, inundation by high tides is shown by filled circles (inner left axis; $n=3 \pm \mathrm{SE}$ ); the mean seawater concentration of bicarbonate is shown by the horizontal dashed line. The phase of the tidal cycle is shown by the solid line (right axis). Dark portions of the photoperiod are shown by the vertical gray bars (from GA Pearson, EA Serrão, SH Brawley, 1998, Control of gamete-release in fucoid algae: sensing hydrodynamic conditions via carbon acquisition, Ecology 79:1725-39).

anion efflux channels in guard cells (Hedrich and Marten 1993; Hedrich and others 1994). Tyrosine phosphorylation also appears to play a role in potentiation, which was effectively blocked by a specific inhibitor of protein tyrosine kinases (neither Ser/Thr kinase inhibitors nor phosphatase inhibitors had any effect).

The results of inhibitor studies discussed above suggest a model in which light-dependent ionic fluxes generate the necessary turgor changes to expel gametangia from within the conceptacle to the exterior. The complexity and size of the receptacle, which contains several different tissues, makes it difficult to frame and test specific hypotheses. However, the general model finds support in a study by Speransky and colleagues (2001) in which energy-dispersive X-ray microanalysis-scanning electron microscopy (EDXSEM) was used to map ionic distributions (primarily
$\mathrm{K}^{+}$and $\mathrm{Cl}^{-}$) within whole receptacles during potentiation and gamete expulsion.

Although gamete release under calm conditions requires active photosynthesis (Serrão and others 1996), and the identification of DIC as the proximal signal in detection of water motion clearly implies a photosynthesis-dependent signaling pathway (Pearson and Brawley 1998; Pearson and others 1998), there is, however, recent evidence that multiple signal input pathways may operate. Again using Silvetia as a model, Pearson and colleagues (2004) investigated the role of light quality during potentiation. These studies led to the proposal that a blue light (BL) responsive photoreceptor is present in Silvetia, which, in the absence of other wavelengths, induces gamete release in the light (normally triggered only by darkness in this system). Furthermore, a specific 

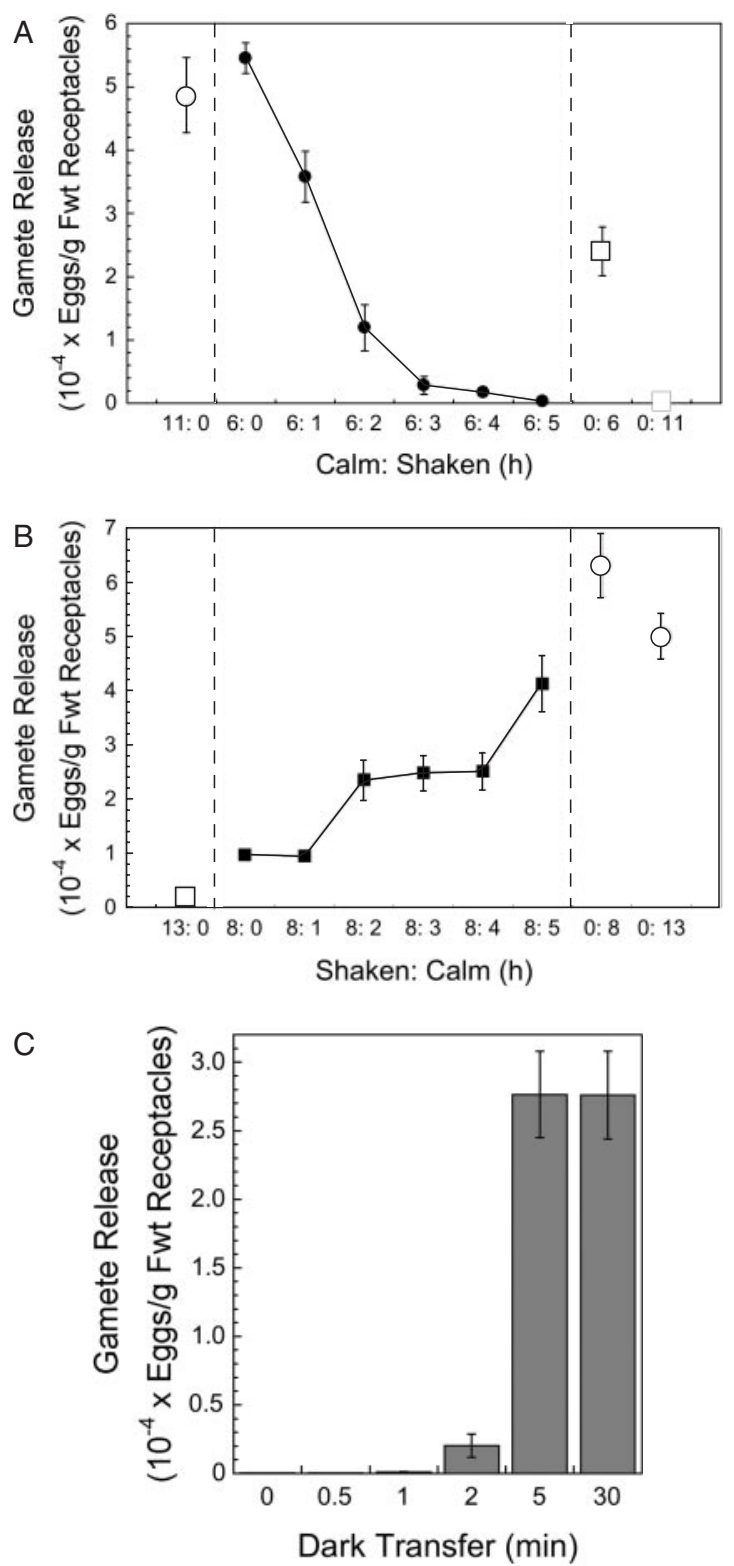

Fig. 4 Reversibility of potentiation by water motion (A and $\mathbf{B})$, and time course of dark-induced gamete release (C) in S. compressa. (A) The effects on potentiation of shaking receptacles following calm conditions (filled circles) and (B) calm following shaking conditions (filled squares). The numbers of gametes released were determined following a 30 min dark transfer after completion of each experimental treatment. Results are shown relative to calm controls (open circles) and shaken controls (open squares). (C) Gamete expulsion from potentiated receptacles following transfer to darkness for periods between 0 and 30 min. Potentiation was for $6 \mathrm{~h}$ in the light. Following dark transfers, receptacles were returned to the light for an additional 30 min to allow for the completion of gamete release. Values are means \pm SE $(n=5)$ (from GA Pearson, EA Serrão, SH Brawley, 1998, A model for signal transduction during gamete release in the fucoid alga Pelvetia compressa, Plant Physiol 118:30513; reprinted with permission of the American Society of Plant Biologists). green light (GL) depotentiation of gamete release (centered near $530 \mathrm{~nm}$ ) was found that is reminiscent of the recently reported BL/GL reversibility of stomatal opening (Frechilla and others 2000). There is a growing body of evidence that zeaxanthin is the BL photoreceptor in BL/GR reversible stomatal responses (Talbott and others 2003, 2006), and the similarity between fucoid gamete release and stomatal responses is intriguing, both at the functional and evolutionary level. Certainly, the finding that both inorganic carbon and quality of light play a signaling role in both systems raises the parsimonious possibility that known gameterelease signal inputs localize to the chloroplast.

The proximal spawning signals so far identified suggest that gamete release should occur synchronously given that individuals experience homogeneous environmental conditions. Periods of inorganic carbonlimited photosynthesis at saturating irradiances and low-flow conditions may be relatively rare in the intertidal zone (other than in tidepools) (Berndt and others 2002), but should coincide either with slack high tide (Berndt and others 2002), or during low tide if exposed algae are hydrated and photosynthetically active (Kawamitsu and Boyer 1999). The BL-GL signals that modify gamete release in Silvetia further suggest slack high tide as being the likely period for release, when light passing through the water column is maximally blue-shifted. However, both high-tide and low-tide release have been observed in this species (Johnson and Brawley 1998; Brawley and others 1999), as discussed below.

Small spatial or temporal variations in environmental conditions may therefore serve to reinforce premating reproductive isolation between potentially hybridizing species with different vertical distributions on intertidal shores, but not, as is commonly the case, where those distributions overlap.

\section{Environmental cycles and synchronous gamete release in natural fucoid populations}

Since the pioneering work of Brawley (1992), several studies have been performed to estimate the timing of gamete release in fucoid algae, mainly within the genus Fucus, and it is worth comparing these, given both the wide geographical and ecological ranges of fucoids. Although we are principally concerned in this review with fucoid reproductive ecology in the intertidal zone of rocky shores, some important studies have been performed in other habitats in which fucoids are found, for example, estuaries (Brawley 1992), and the non-tidal Baltic Sea (Serrão and others 1996), as well as intertidal species restricted to tidepools 
(Pearson and Brawley 1996). Published data on the timing and periodicity of gamete release from natural intertidal populations experiencing tidal immersion/ emersion cycles are few (Johnson and Brawley 1998; Berndt and others 2002; Ladah and others 2003; Monteiro and others, unpublished data).

All the published works for natural populations of fucoids reports sharp peaks of release (or settlement, which directly follows release, since fucoids lack a planktonic stage and have negatively buoyant eggs) on a daily timescale, usually with a semilunar periodicity (Brawley 1992; Pearson and Brawley 1996; Berndt and others 2002; Monteiro and others, unpublished data). The phase of the fortnightly periodicity of spawning in intertidal populations in relation to new and full moon varies from site to site and species to species. This is an indication that tidal and light-dark cycles, rather than semilunar cues (that is, spring-neap tides) may be used to entrain spawning rhythms (Yamahira 2004). For example, in Maine (USA), F. distichus in tidepools follows a roughly semilunar periodicity in which release coincides with daytime low neap tides (Pearson and Brawley 1996), whereas intertidal $F$. vesiculosus releases mainly around full and new moon (Fig. 5) (Serrão 1996; Berndt and others 2002). However, we now know that the timing of release with respect to semilunar phase varies across the geographic range within a species; for example, on the Atlantic coast of Portugal, semilunar periodicity in F. vesiculosus

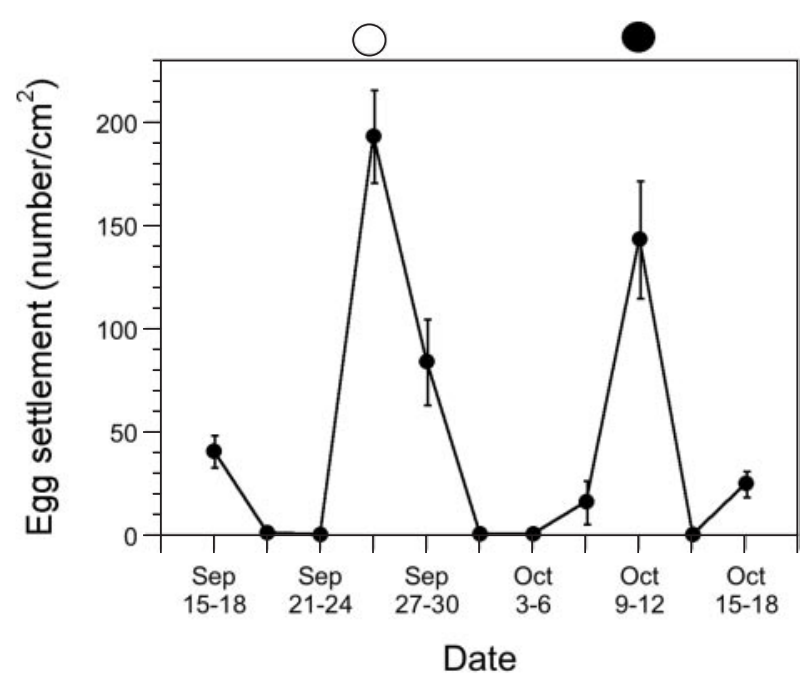

Fig. 5 Semilunar periodicity of gamete release during September-October 1992 from intertidal F. vesiculosus at Castine Bay, Maine, USA. Gamete release was estimated from settlement on artificial substrates designed to trap gametes and zygotes on a rugose surface. Lunar phase is shown at the top of the plot (open circle: full moon; filled circle: new moon). Values are means \pm SE $(n=10)$ (from EA Serrão, 1996, Reproductive ecology of Fucus vesiculosus L. in the Baltic Sea, PhD thesis, University of Maine). is centered on neap tide periods occurring around the waxing and waning quarter moons (Monteiro and others, unpublished data).

Data on the periodicity of gamete release from several locations would allow testing of the fitnesscomponent model (Yamahira 2004) in the Atlantic due to the strong north-south gradient in the timing of the tides. In June, the spring high tide at full and new moon in Portugal occurs $\sim 9 \mathrm{~h}$ after sunrise, whereas in Brittany, France, it occurs $\sim 12.5 \mathrm{~h}$ after sunrise. In Maine, on the western side of the Atlantic, the equivalent high tide occurs $6.5 \mathrm{~h}$ after sunrise. This leads to a simple prediction that peaks in gamete release will be offset relative to the lunar phase by several days between these 2 sites if tidal and light-dark cycles entrain the rhythm. Alternatively, if semilunar cues entrain the response, no geographic variation in phase relative to new and full moon is expected, although the timing of peak spawning in the light-dark cycle may vary.

Gamete release at low tide has long been observed in fucoids (discussed by Fritsch 1945, p 376-7), the possible significance of which was the subject of a previous review (Brawley and others 1999). As mentioned above, some species appear to have periods of both low-tide and high-tide gamete release (for example, S. compressa) (Johnson and Brawley 1998). Since hermaphroditic fucoids are capable of self-fertilization (Pollock 1970; personal observations of selfing in Fucus spiralis), gamete release at low tide may increase reproductive assurance if sufficient seawater is present for the gametangia to break down and fertilization to occur. It could be argued that this might be maintained if diversifying selection in some habitats allowed for longer distance dispersal (high-tide release), and simultaneously retained a greater reproductive assurance (low-tide release).

For dioecious species in which gametes cannot routinely come into contact while adults are exposed, the effectiveness of gamete release at low tide initially appears more difficult to support, despite being commonly observed in dense stands of Ascophyllum nodosum and F. vesiculosus (Berndt and others 2002). However, it is possible that some fertilization could occur in dense populations in which male and female fronds are intertwined, given that sufficient seawater is present for gametangial breakdown as mentioned above. Furthermore, the initial mixing of gametes during reimmersion under this scenario would occur in limited water volumes with oscillatory flow. Given reasonably calm conditions, this might provide for high fertilization success if gametes are mixed at relatively high concentrations near the substrate, where the negatively buoyant eggs could become trapped in 
microtopographical features under boundary-layer conditions. The balance between enhancement and inhibition of external fertilization in near-shore hydrodynamic conditions remains somewhat unclear [for negative and positive effects of turbulent flows see Denny and Shibata (1989) and Denny and colleagues (1992), respectively]. The assumption that external fertilization is exclusively a water column process has recently been challenged by the finding that the majority of sea urchin eggs are fertilized in masses either still on the female or in the adjacent boundary flow (Yund and Meidel 2003). In general, in situ studies of natural spawning in species that broadcast eggs and sperm (Brawley 1992; Pearson and Brawley 1996; Serrão and others 1996; Berndt and Brawley 2002; Yund and Meidel 2003) tend to contradict the generally held assumption that sperm limitation is a common feature of this mode of reproduction (reviewed by Levitan and Petersen 1995; Levitan and Sewall 1998; Yund 2000).

\section{Synchrony during single spawning events}

The extent of synchrony during a spawning event (that is, during a single tide) could exert a major influence on population dynamics and population genetic structure through its effects on gamete and/or zygote dispersal shadows as well as on the genetic constitution of the gamete pool available for syngamy. In addition, for species complexes in which sibling species have extensive sympatric distributions, as well as a welldocumented capacity for hybridization (Coyer and others 2002; Engel and others 2005), it can also play an important role in ongoing reproductive isolation and/or speciation. Some of these questions are developed below, and where the extent of our understanding is limited, the prospects of developing fucoids as models in which to address them is assessed.

\section{Who is spawning?}

While the data currently available can provide some indication as to the temporal patterns of spawning, they are integrated measures of groups/populations, with no capacity to resolve individual contributions. Generally, this lack of data is an important gap in our knowledge, not only for fucoids but also in natural populations of sessile broadcast-spawning organisms. The contribution of a large proportion of reproductive individuals to a spawning event has very different implications for population genetic structure than a spawning event in which a few individuals contribute disproportionately. This leads to very different expectations for effective population size, and could result in local heterozygote deficits and lead to the temporal
Wahlund effects suggested by recent population genetic studies (Coyer and others 2003; Engel and others 2005). This question could be resolved for natural populations by experiments retaining released gametes (for example, by the use of fine mesh bags enclosing receptacles-see Pearson and Brawley 1996), although this would require intensive sampling to estimate intraindividual and interindividual variance.

\section{Spawning synchrony, hybridization, and reproductive isolation}

Within the most species-rich fucoid genus, Fucus, several species are sympatric throughout much of their respective ranges (Lüning 1990), for example, F. vesiculosus, Fucus spiralis, and F. evanescens in the western Atlantic, and F. vesiculosus, F. spiralis, and F. serratus in the eastern Atlantic. The pairs F. vesiculosus/F. spiralis and F. serratus/F. evanescens belong to well-resolved sister clades (Serrão and others 1999), and divergence time seems to have been sufficient for the evolution of prezygotic fertilization barriers (Kniep 1925; Bolwell and others 1977; but see Burrows and Lodge 1951, 1953). However, within each clade hybrids form in natural populations (Coyer and others 2002; Engel and others 2005), as suggested by laboratory crosses (Kniep 1925; Coyer and others 2002), and supported both by observations of intermediate morphological phenotypes in natural populations (Burrows and Lodge 1951; Scott and Hardy 1994), by the detection of intermediate genotypes using molecular markers (Coyer and others 2002; Wallace and others 2004, 2006; Engel and others 2005, 2006), and mismatch between the genotype and sexual phenotype (Billard and others 2005b; Engel and others 2005). The sibling species F. vesiculosus and F. spiralis have to date shown no fixed genetic differences at nuclear or organellar loci (Serrão and others 1999; Coyer and others 2006), but were recently shown to be distinct genetic entities based on allelic frequencies, corresponding to morphospecies (Billard and others 2005a). The results of Billard and colleagues (2005b) suggest that fitness reductions in hybrids may not be large, since putative hybrids were found to have all 3 sexual phenotypes (that is, male, female, and cosexual). This is reported to occur rarely in first generation crosses (Westergaard 1958), and suggests the presence of F2 or backcrossed individuals. The absence of (prezygotic) fertility differences between hybrids and parental species further supports the hypothesis that hybrids are fit (Billard and others 2005b).

It is interesting that within both clades, hermaphroditic and dioecious lineages have diverged. The observation that closely related taxa often have contrasting 
reproductive strategies suggest that alterations in mating system between lineages promotes the development of reproductive isolation and speciation (Barrett 1998; Dorken and others 2002; Engel and others 2005). While variation in mating system itself may thus account for a large proportion of prezygotic reproductive isolation, small variations in the timing of synchronous gamete release between species, as observed in some sympatric, interfertile invertebrates (Harrison and others 1984; Hayashibara and others 1993; Fukami and others 2003; Levitan and others 2004; Wolstenholme 2004) may play an important role. For the potentially interfertile and sympatric fucoids F. vesiculosus and F. spiralis (Engel and others 2005), spawning synchrony between the 2 species at the semilunar time scale in sympatric populations is striking (Monteiro and others, unpublished data). However, the existence and extent of interspecific spawning asynchrony during single spawning events remains unknown. Should observations reveal asynchrony between the species at the same shore level (that is, in mixed stands experiencing similar environmental cues), then it would be interesting to test for reproductive character displacement by comparing levels of spawning asynchrony between sympatric and allopatric populations.

\section{Spawning synchrony in the intertidal zone: a recruitment-assurance component?}

Intertidal species with restricted vertical distributions inhabit a nearly one-dimensional habitat, and the capacity to restrict (vertical) dispersal might be an important life-history trait that limits wastage of zygotes. Gamete release that is restricted to calm conditions, negatively buoyant eggs, and negatively phototactic sperm are all characteristics that suggest limited gamete dispersal, predictions that are supported by empirical observations in the field (Serrão and others 1997; Dudgeon and Petraitis 2001; Dudgeon and others 2001; Marshall and others 2004), as well as by local patterns of genetic structure (Coleman and Brawley 2005a; Coleman and Brawley 2005b; Engel and others 2005).

The occurrence of different reproductive modes within the genus Fucus (all other genera of the family Fucaceae are invariant for reproductive mode) provides an opportunity to test an evolutionary hypothesis related to spawning synchrony: Is there selection on synchronous spawning for recruitment assurance? The test is based on the simple idea that, all other things being equal (that is, in the same environment), spawning synchrony in obligate outcrossers should be under greater selection than in selfing hermaphrodites, since the latter have no need for other individuals for reproductive assurance.

What is the evidence that reproduction is predominantly via selfing in hermaphroditic Fucus spp.? First, sperm:egg ratios are $\sim 10 \times$ lower in F. spiralis than in the dioecious F. vesiculosus (Vernet and Harper 1980; Billard and others 2005b), well within the typical range of pollen:ovule ratios of selfing plants (Cruden 1977). Second, estimates of genetic diversity suggest that selfing and/or inbreeding are important or predominant reproductive modes (Coleman and Brawley 2005a; Engel and others 2005). Further evidence may be inferred from the observation that, near the southern limit of distribution in Portugal, F. spiralis persists on moderately exposed rocky shores often at low densities (Ladah and others 2003; G. Pearson and E. Serrão, personal observations of species distributions), while F. vesiculosus is restricted to estuaries and salt marshes.

No directly comparable data for duration of spawning in hermaphroditic versus dioecious fucoids are available. In the hermaphroditic tidepool species, F. distichus, the duration of spawning events during neap low tides were estimated directly from the gamete release-settlement relationship, and from estimates of fertilization time (using sperm pronuclear migration rates). Average spawning periods were $\sim 4-4.5 \mathrm{~h}$ (Pearson and Brawley 1996) in the calm water of exposed tidepools. These data can be compared with spawning in intertidal and estuarine populations of dioecious $F$. vesiculosus, estimated from water column samples obtained by pumping (Berndt and others 2002). Intact (that is, recently released) oogonia were found over periods of $2-3 \mathrm{~h}$ at intertidal stations, and eggs were found over a slightly shorter interval in an estuary. These results provide tentative support for the idea that spawning periods may be more constrained (synchronous) in dioecious than in hermaphroditic species, with 2 important caveats. First, the habitats are not directly comparable; tidepools switch abruptly from turbulent to calm conditions, the latter persisting throughout low-tide exposure. More gradual changes in currents and in turbulence regimes occur in the intertidal, while estuaries have the added complication of tidal variation in salinity (Brawley 1992). Second, Berndt and colleagues (2002) reported seawater temperatures of $8-12^{\circ} \mathrm{C}$ during autumn sampling, while the winter-reproducing F. distichus commonly spawns at $0-5^{\circ} \mathrm{C}$ (Pearson and Brawley 1996). Low temperature significantly extends zygote settlement (adhesion) times in F. distichus (Pearson and Brawley 1996; Coleman and Brawley 2005b), partially compensating for the lack of dispersal of gametes in tidepool habitats (Marshall and others 2004). 
The hypothesis that spawning synchrony is selectively maintained for recruitment assurance (limited offshore dispersal) in the intertidal zone is nested within (contingent upon) the reproductive assurance (that is, fertilization success) hypothesis. While recruitment success in fucoids may generally be poor (Vadas and others 1990; Jenkins and others 1999; Dudgeon and Petraitis 2001; Ladah and others 2003; Dudgeon and Petraitis 2005), we suggest that synchronous spawning may be critical for maintaining an adequate propagule supply within the restricted vertical habitat range of intertidal fucoids, notwithstanding the various biotic and abiotic challenges early recruitment stages face. The most direct test of the relative importance of each process would come from comparative studies of temporal and interindividual spawning using the sister species F. vesiculosus and F. spiralis which have contrasting mating systems (see Who is spawning? above). A similar degree of interindividual synchrony in gamete release between both mating systems would provide support for the hypothesis that recruitment assurance is a significant factor acted upon by selection in the intertidal zone. Such support would be strengthened in populations (or experimental conditions) with relaxed environmental constraints (for example, sheltered conditions with greater and more frequent "windows of opportunity" for spawning).

In summary, fucoid algae are an attractive system for studies of reproductive ecology and evolution of life history. Their capacity to couple adult and early stages of the life cycle through external fertilization in the unforgiving environment of the intertidal zone, as well as the presence of sibling species, occurrence of hybridization and/or recent reproductive isolation, all provide a range of fascinating questions. Many questions remain, but a critical mass of research in several areas (reproductive ecology, spawning mechanisms, molecular markers, and population genetics) is generating the tools and the conceptual basis necessary for future advances in understanding.

\section{Acknowledgments}

We would like to express our thanks to the Symposium organizers, Amy Moran and Robert Podolsky, for the invitation to participate in the SICB Symposium "Integrating Function Over Marine Life Cycles." Some of this research was the outcome of projects funded by the Portuguese Science Foundation (FCT) and FEDER, and EU Network of Excellence, Marine Genomics Europe, for which the authors are grateful. We are also grateful to the NSF-CORONA network for stimulating discussions. We are grateful to 2 anonymous reviewers whose comments and suggestions improved the original manuscript.

Conflict of interest: None declared.

\section{References}

Assmann SM. 1993. Signal transduction in guard cells. Annu Rev Cell Biol 9:345-75.

Babcock RC, Bull GD, Harrison PL, Heyward AJ, Oliver JK, Wallace AL, Willis BL. 1986. Synchronous spawnings of 105 scleractinian coral species on the Great Barrier Reef. Mar Biol 90:379-94.

Barrett SCH. 1998. The evolution of mating strategies in flowering plants. Trends Plant Sci 3:335-41.

Berndt M-L, Callow JA, Brawley SH. 2002. Gamete concentrations and timing and success of fertilization in a rocky shore seaweed. Mar Ecol Prog Ser 226:273-85.

Billard E, Daguin C, Pearson G, Serrão E, Engel C, Valero M. 2005a. Genetic isolation between three closely related taxa: Fucus vesiculosus, F. spiralis, and F. ceranoides (Phaeophyceae). J Phycol 41:900-5.

Billard E, Serrão EA, Pearson GA, Engel CR, Destombe C, Valero M. 2005b. Analysis of sexual phenotype and prezygotic fertility in natural populations of Fucus spiralis, F. vesiculosus (Fucaceae, Phaeophyceae) and their putative hybrids. Eur J Phycol 40:397-407.

Bolwell GP, Callow JA, Callow ME, Evans LV. 1977. Crossfertilization in fucoid seaweeds. Nature 268:626-7.

Brawley SH. 1992. Fertilization in natural populations of the dioecious brown alga Fucus ceranoides and the importance of the polyspermy block. Mar Biol 113:145-57.

Brawley SH, Johnson LE, Pearson GA, Speransky V, Li R, Serrão E. 1999. Gamete release at low tide in fucoid algae: maladaptive or advantageous? Am Zool 39:218-29.

Burrows EM, Lodge SM. 1951. Autecology and the species problem in Fucus. J Mar Biol Assoc UK 30:161-75.

Burrows EM, Lodge SM. 1953. Culture of Fucus hybrids. Nature 172:1009-10.

Caspers H. 1984. Spawning periodicity and habitat of the Palolo worm Eunice viridis in the Samoan Islands. Mar Biol 79:229-36.

Coleman MA, Brawley SH. 2005a. Are life history characteristics good predictors of genetic diversity and structure? A case study of the intertidal alga Fucus spiralis (Heterokontophyta; Phaeophyceae) J. Phycol 41:753-62.

Coleman MA, Brawley SH. 2005b. Spatial and temporal variability in dispersal and population genetic structure of a rockpool alga. Mar Ecol Prog Ser 300:63-77.

Coyer JA, Hoarau G, Oudot-Le Secq M-P, Stam WT, Olsen JL. 2006. A mtDNA-based phylogeny of the brown algal genus Fucus (Heterokontophyta; Phaeophyta). Mol Phylog Evol 39:209-22.

Coyer JA, Peters AF, Hoarau G, Stam WT, Olsen JL. 2002. Hybridization of the marine seaweeds, Fucus serratus and Fucus evanescens (Heterokontophyta: Phaeophyceae) in a 
100-year-old zone of secondary contact. Proc R Soc Lond B 269:1829-34.

Coyer JA, Peters AF, Stam WT, Olsen JL. 2003. Post-ice age recolonization and differentiation of Fucus serratus L. (Phaeophyceae; Fucaceae) populations in Northern Europe. Mol Ecol 12:1817-29.

Cruden RW. 1977. Pollen-ovule ratios: a conservative indicator of breeding systems in flowering plants. Evolution 31:32-46.

Denny M, Dairiki J, Distefano S. 1992. Biological consequences of topology on wave-swept rocky shores: I. Enhancement of external fertilization. Biol Bull 183:220-32.

Denny MW, Shibata MF. 1989. Consequences of surf-zone turbulence for settlement and external fertilization. Am Nat 134:859-89.

Dorken ME, Friedman J, Barrett SCH. 2002. The evolution and maintenance of monoecy and dioecy in Sagittaria latifolia (Alismataceae). Evolution 56:31-41.

Dudgeon S, Kübler JE, Wright WA, Vadas RL, Petraitis PS. 2001. Natural variability in zygote dispersal of Ascophyllum nodosum at small spatial scales. Funct Ecol 15:595-604.

Dudgeon S, Petraitis PS. 2001. Scale-dependent recruitment and divergence of intertidal communities. Ecology 82:991-1006.

Dudgeon S, Petraitis PS. 2005. First year demography of the foundation species, Ascophyllum nodosum, and its community implications. Oikos 109:405-15.

Engel CR, Daguin C, Serrão EA. 2005. Genetic entities and mating system in hermaphroditic Fucus spiralis and its close dioecious relative F. vesiculosus (Fucaceae, Phaeophyceae). Mol Ecol 14:2033-46.

Engel CR, Daguin C, Serrão E. 2006. When is a hybrid a hybrid? (a counter-reply to Wallace et al.). Mol Ecol (in press).

Frechilla S, Talbott LD, Bogomolni RA, Zeiger E. 2000. Reversal of blue light-stimulated stomatal opening by green light. Plant Cell Physiol 41:171-6.

Fritsch FE. 1945. The structure and reproduction of the algae. Vol 2. Cambridge, UK: Cambridge University Press.

Fukami H, Omori M, Shimoike K, Hayashibara T, Hatta M. 2003. Ecological and genetic aspects of reproductive isolation by different spawning times in Acropora corals. Mar Biol 142:679-84.

Gardner JPA. 1997. Fertilization in the sea. Adv Mar Biol 31:1-78.

Harrison PL, Babcock RC, Bull GD, Oliver JK, Wallace CC, Willis BL. 1984. Mass spawning in tropical reef corals. Science 223:1186-9.

Hayashibara T, Shimoike K, Kimura T, Hosaka S, Heyward AJ, Harrison PL, Kudo K, Omori M. 1993. Patterns of coral spawning at Akajima Island, Okinawa, Japan. Mar Ecol Prog Ser 101:253-62.

Hedrich R, Marten I. 1993. Malate-induced feedback regulation of plasma membrane anion channels could provide a $\mathrm{CO}_{2}$ sensor to guard cells. EMBO J 12:897-901.

Hedrich R, Marten I, Lohse G, Dietrich P, Winter H, Lohaus G, Heldt H-W. 1994. Malate-sensitive anion channels enable guard cells to sense changes in the ambient $\mathrm{CO}_{2}$ concentration. Plant J 6:741-8.

Jaffe LF. 1954. Stimulation of the discharge of gametangia from a brown alga by a change from light to darkness. Nature 174:743.

Jenkins SR, Norton TA, Hawkins SJ. 1999. Interactions between canopy forming algae in the eulittoral zone of sheltered rocky shores on the Isle of Man. J Mar Biol Assoc UK 79:341-9.

Johnson LE, Brawley SH. 1998. Dispersal and recruitment of a canopy-forming intertidal alga: the relative roles of propagule availability and post-settlement processes. Oecologia 117:517-26.

Kawamitsu Y, Boyer JS. 1999. Photosynthesis and carbon storage between tides in a brown alga, Fucus vesiculosus. Mar Biol 133:361-9.

Kinlan BP, Gaines SD. 2003. Propagule dispersal in marine and terrestrial environments: a community perspective. Ecology 84:2007-20.

Kniep H. 1925. Uber Fucus bastarde. Flora 118:331-8.

Ladah L, Bermudez R, Pearson G, Serrão E. 2003. Fertilization success and recruitment of dioecious and hermaphroditic fucoid seaweeds with contrasting distributions near their southern limit. Mar Ecol Prog Ser 262:173-83.

Levitan DR, Fukami H, Jara J, Kline D, McGovern TM, McGhee KE, Swanson CA, Knowlton N. 2004. Mechanisms of reproductive isolation among sympatric broadcastspawning corals of the Montastraea annularis species complex. Evolution 58:308-23.

Levitan DR, Petersen C. 1995. Sperm limitation in the sea. Trends Ecol Evol 10:228-31.

Levitan DR, Sewell MA. 1998. Fertilization success in freespawning marine invertebrates: review of the evidence and fisheries implications. Can Spec Publ Fish Aquat Sci 125:159-64.

Levitan DR, Sewell MA, Chia F-S. 1992. How distribution and abundance influence fertilization success in the sea urchin Strongylocentrotus franciscanus. Ecology 73:248-54.

Lüning K. 1990. Seaweeds. Their environment, biogeography, and ecophysiology. New York: Wiley.

Marshall DJ, Semmens D, Cook C. 2004. Consequences of spawning at low tide: limited gamete dispersal for a rockpool anemone. Mar Ecol Prog Ser 266:135-42.

Morgan SG, Christy JH. 1994. Plasticity, constraint, and optimality in reproductive timing. Ecology 75:2185-203.

Palumbi SR. 2004. Marine reserves and ocean neighborhoods: the spatial scale of marine populations and their management. Annu Rev Environ Resour 29:31-68.

Pearson GA, Brawley SH. 1996. Reproductive ecology of Fucus distichus (Phaeophyceae): an intertidal alga with successful external fertilization. Mar Ecol Prog Ser 143:211-23.

Pearson GA, Brawley SH. 1998. A model for signal transduction during gamete release in the fucoid alga Pelvetia compressa. Plant Physiol 118:305-13. 
Pearson GA, Serrão EA, Brawley SH. 1998. Control of gamete release in fucoid algae: sensing hydrodynamic conditions via carbon acquisition. Ecology 79:1725-39.

Pearson GA, Serrão EA, Dring MJ, Schmid R. 2004. Blue- and green-light signals for gamete release in the brown alga, Silvetia compressa. Oecologia 138:193-201.

Pennington JT. 1985. The ecology of fertilization of echinoid eggs: the consequences of sperm dilution, adult aggregation, and synchronous spawning. Biol Bull 169:417-30.

Pollock EG. 1970. Fertilization in Fucus. Planta 92:85-99.

Scott GW, Hardy FG. 1994. Observations of the occurrence of hybrids between two sympatric species of fucoid algae. Cryptogam Algol 15:297-305.

Serrão EA. 1996. Reproductive ecology of Fucus vesiculosus L. in the Baltic Sea. PhD thesis. University of Maine.

Serrão EA, Alice LA, Brawley SH. 1999. Evolution of the Fucaceae (Phaeophyceae) inferred from nrDNA-ITS. J Phycol 35:382-94.

Serrão EA, Kautsky L, Lifvergren T, Brawley SH. 1997. Gamete dispersal and pre-recruitment mortality in Baltic Fucus vesiculosus. Phycologia 36:101-2 (Abstract).

Serrão EA, Pearson G, Kautsky L, Brawley SH. 1996. Successful external fertilization in turbulent environments. Proc Natl Acad Sci USA 93:5286-90.

Skov MW, Hartnoll RG, Ruwa RK, Shunula JP, Vannini M, Cannicci S. 2005. Marching to a different drummer: crabs synchronize reproduction to a 14-month lunar-tidal cycle. Ecology 86:1164-71.

Speransky VV, Brawley SH, McCully ME. 2001. Ion fluxes and modification of the extracellular matrix during gamete release in fucoid algae. J Phycol 37:555-73.

Talbott LD, Hammad JW, Harn LC, Nguyen VH, Patel J, Zeiger E. 2006. Reversal by green light of blue light stimulated stomatal opening in intact, attached leaves of Arabidopsis operates only in the potassium-dependent, morning phase of movement. Plant Cell Physiol 47:32-9.

Talbott LD, Shmayevich IJ, Chung Y, Hammad JW, Zeiger E. 2003. Blue light and phytochrome-mediated stomatal opening in the npq1 and phot 1 phot 2 mutants of Arabidopsis. Plant Physiol 133:1522-9.

Vadas RL, Wright WA, Miller SL. 1990. Recruitment of Ascophyllum nodosum: wave action as a source of mortality. Mar Ecol Prog Ser 61:263-72.

Vernet P, Harper JL. 1980. The costs of sex in seaweeds. Biol J Linn Soc 13:129-38.

Wallace AL, Klein AS, Mathieson AC. 2004. Determining the affinities of salt marsh fucoids using microsatellite markers: evidence of hybridization and introgression between two species of Fucus (Phaeophyta) in a Maine estuary. J Phycol 40:1013-27.

Wallace AL, Klein AS, Mathieson AC. 2006. A reply to Engel et al. Mol Ecol 15:1185-7.

Westergaard M. 1958. The mechanisms of sex determination in dioecious flowering plants. Adv Genet 9:217-81.

Wolstenholme JK. 2004. Temporal reproductive isolation and gametic compatibility are evolutionary mechanisms in the Acropora humilis species group (Cnidaria; Scleractinia). Mar Biol 144:567-82.

Yamahira K. 2004. How do multiple environmental cycles in combination determine reproductive timing in marine organisms? A model and test. Funct Ecol 18:4-15.

Yund PO. 2000. How severe is sperm limitation in natural populations of marine free-spawners? Trends Ecol Evol 15:10-3.

Yund PO, Meidel SK. 2003. Sea urchin spawning in benthic boundary layers: are eggs fertilized before advecting away from females? Limnol Oceanogr 48:795-801. 